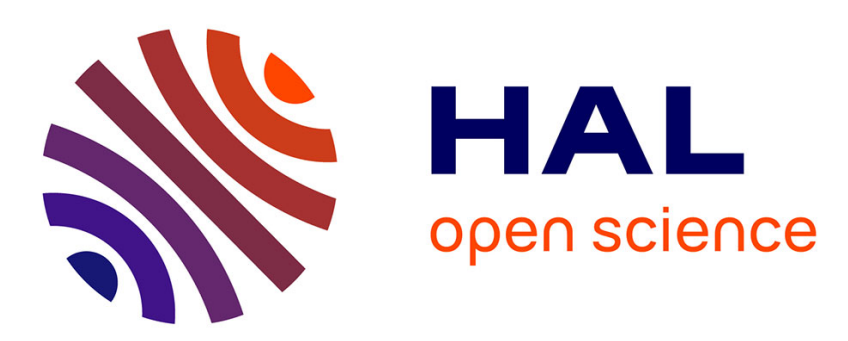

\title{
Study and comparison of non linear and LPV control approaches for vehicle stability control
}

Soheib Fergani, Lghani Menhour, Olivier Sename, Luc Dugard, Brigitte d'Andréa-Novel

\section{- To cite this version:}

Soheib Fergani, Lghani Menhour, Olivier Sename, Luc Dugard, Brigitte d'Andréa-Novel. Study and comparison of non linear and LPV control approaches for vehicle stability control. MED 2013 - 21st Mediterranean Conference on Control and Automation, Jun 2013, Platanias-Chania, Crete, Greece. hal-00868229

\section{HAL Id: hal-00868229 \\ https://hal.science/hal-00868229}

Submitted on 1 Oct 2013

HAL is a multi-disciplinary open access archive for the deposit and dissemination of scientific research documents, whether they are published or not. The documents may come from teaching and research institutions in France or abroad, or from public or private research centers.
L'archive ouverte pluridisciplinaire HAL, est destinée au dépôt et à la diffusion de documents scientifiques de niveau recherche, publiés ou non, émanant des établissements d'enseignement et de recherche français ou étrangers, des laboratoires publics ou privés. 


\title{
Study and comparison of non linear and LPV control approaches for vehicle stability control.
}

\author{
S. Fergani ${ }^{1 *}$, L. Menhour ${ }^{2}$, O. Sename ${ }^{1}$, L. Dugard ${ }^{1}$, B. D’Andrea Novel ${ }^{3}$
}

\begin{abstract}
This paper proposes a study and a comparison between two efficient and relatively recent vehicle control dynamics strategies, namely, the non linear Flatness control strategy and the $\mathrm{LPV} / \mathcal{H}_{\infty}$ control strategy. The first one concerns a controller based on the differential algebraic flatness of non linear systems and an algebraic non linear estimation applied to commercial vehicles. The second one is a $\mathrm{LPV} / \mathcal{H}_{\infty}$ (Linear Varying Parameter with the $\mathcal{H}_{\infty}$ norm ) control using a stability monitoring system to achieve the vehicle dynamics control objective. These two strategies use Active Steering and Electro-Mechanical Braking actuators and aim at improving the vehicle stability and steerability by designing a multivariable controller that acts simultaneously on the lateral and longitudinal dynamics of the car.

Simulations are performed on a complex nonlinear full vehicle model, the same driving scenario is applied for the two control strategies. The model parameters are those of a Renault Mégane Coupé, obtained by identification with real data. Promising simulations results are obtained. Comparison between the two proposed strategies and the uncontrolled vehicle show the reliability and the robustness of the proposed solutions, even if one is developed within the linear control framework while the other one is a non linear control approach.
\end{abstract}

\section{INTRODUCTION}

Road safety is a major challenge in the automotive industry, that, together with road improvements and passive safety (car mechanical structure, safety belts ...) can be reached thanks to the intelligent control of new actuators that change the vehicle dynamical behavior on-line (such as active steering, braking, suspensions, ...). Recently, research works focused on preventing the car from critical situations such as drifting, spinning or rolling over. While automotive systems involve several dynamics, vehicle safety is mainly linked to lateral and longitudinal movements. Many recent works have dealt either with longitudinal car behavior through slip and wheel dynamics leading to many efficient strategies as ABS and ESP [1]-[4], or with the lateral and yaw based control for handling and safety performance improvements. In the latter case the control structure may include either steering actuators (mainly front and rear) [5]-[8] or braking

\footnotetext{
1 GIPSA-lab, Control Systems Department, Grenoble Grenoble INP, ENSE ${ }^{3}$ - Domaine Universitaire BP46, 38402 Saint Martin d'Hères - Cedex France. soheib.ferganiegipsa-lab.grenoble-inp. fr

2 Centre de Recherche STIC, Institut Univeristaire de Technologie de Troyes, 9, Rue du Québec, 10000 Troyes, France. lghani.menhoureuniv-reims.fr

3 Mines-ParisTech, CAOR-Centre de Robotique, Mathématiques et systèmes, 60 boulevard Saint-Michel, 75272 Paris cedex 06, France. brigitte. dandrea-novel@mines-paristech. fr

* This work was supported by the French national project INOVE/ ANR 2010 BLAN 0308. Corresponding author: olivier.senamedgipsa-lab.grenoble-inp.fr
}

actuators (eventually at the four wheels) [9], [10]. Few recent works have been concerned with the use of both steering and braking actions as explained in [11]. Let us mention, among others, [12] where control allocation is considered for the optimal distribution of the control actions, or [13] where an a posteriori braking/steering control distribution is devised.

This paper focuses on collaborative multivariable control, as in the authors previous works [14], [15], and [16] using both braking and steering actuators, which remains a very interesting issue for the global chassis control improvements. In this work, two approaches for the global chassis control are compared: the first one is an LPV/H $\mathcal{H}_{\infty}$ control strategy involving Active Steering and Electro-Mechanical Braking actuators. This approach uses a stability index, based on a sideslip dynamics monitoring system [9], to schedule the activation of the braking and/or steering actuators. It allows a hierarchical use of these actuators depending on driving situation and stability evaluation of the vehicle. The second strategy is a non linear flatness based control. It uses the differential flatness of the nonlinear models [17] (see also [18], [19] for a related approach) and the algebraic nonlinear estimation techniques [20], [21]. This approach is based on a non linear three degrees-of-freedom model. It also uses the algebraic estimation techniques to estimate the derivatives and filtering of noisy signals. This control is suitable to perform some coupled maneuvers like obstacle avoidance via steering control combined with stop-and-go control via braking or driving wheel torque.

The paper is organised as follows: Section $I$ provides the introduction and the notations used in the paper. Section $I I$ briefly presents the vehicle models used for synthesis and validation purpose, namely, an extended bicycle model (for the LPV strategy) and a 3DoF-NLTWVM ("3DoF Nonlinear Two Wheels Vehicle Control Model" for the flatness strategy). Section III is devoted to the controllers design, for both $\mathrm{LPV} / \mathcal{H}_{\infty}$ and flatness control strategies, to enhance the vehicle performances and improve car's dynamics.

The performance analysis is done in Section $I V$ with time domain results simulations for the two proposed approaches performed on the complex nonlinear full vehicle model subject to the same driving scenario. Conclusions and discussions are given in the last Section.

\section{Paper notations:}

Throughout the paper, the following notations will be adopted: indices $i=\{f, r\}$ and $j=\{l, r\}$ are used to identify vehicle front, rear and left, right positions re- 


\begin{tabular}{lccl}
\hline Symbol & Value & Unit & Signification \\
\hline \hline$m_{s}$ & 350 & $\mathrm{~kg}$ & suspended mass \\
$m_{u s_{f j}}$ & 35 & $\mathrm{~kg}$ & front unsprung mass \\
$m_{u s_{r j}}$ & 32.5 & $\mathrm{~kg}$ & rear unsprung mass \\
$I_{x} ; I_{y} ; I_{z}$ & $250 ; 1400 ; 2149$ & $\mathrm{~kg} \cdot \mathrm{m}^{2}$ & roll, pitch, yaw inertia \\
$I_{w}$ & 1 & $\mathrm{~kg} \cdot \mathrm{m}^{2}$ & wheel inertia \\
\hline$t_{f} ; t_{r}$ & $1.4 ; 1.4$ & $\mathrm{~m}$ & front, rear axle \\
$l_{f} ; l_{r}$ & $1.4 ; 1$ & $\mathrm{~m}$ & COG-front, rear distance \\
$R$ & 0.3 & $\mathrm{~m}$ & nominal wheel radius \\
$h$ & 0.4 & $\mathrm{~m}$ & chassis height \\
\hline & & & \\
$V_{x}, V_{y}$ & - & $\mathrm{km} / \mathrm{h}$ & longi/lateral speeds \\
$a_{x}, a_{y}$ & - & $\mathrm{m} / \mathrm{s}^{2}$ & longi/lateral accelerations \\
$\psi$ & - & {$[\mathrm{rad} / \mathrm{s}]$} & yaw angle \\
$\dot{\psi}$ & - & {$[\mathrm{rad}]$} & yaw rate \\
$\omega_{i}$ & - & {$[\mathrm{rad} / \mathrm{s}]$} & wheel $i$ angular speed \\
$T_{\omega}$ & - & {$[\mathrm{Nm}]$} & wheel torque \\
$T_{m}$ & - & {$[\mathrm{Nm}]$} & wheel traction torque \\
$T_{b}$ & - & {$[\mathrm{Nm}]$} & wheel braking torque \\
$T_{b f}$ & - & {$[\mathrm{Nm}]$} & front braking torques \\
$T_{b r}$ & - & {$[\mathrm{Nm}]$} & rear braking torques \\
$\delta$ & - & {$[\mathrm{deg}]$} & wheel steer angle \\
$F_{(x, y) i}$ & - & {$[\mathrm{N}]$} & longi/lateral forces \\
$F_{(x, y)}$ & - & {$[\mathrm{N}]$} & longi/lateral forces \\
$M_{z}$ & - & {$[\mathrm{Nm}]$} & yaw moment \\
\hline & & &
\end{tabular}

TABLE I

Renault MÉgane Coupé Parameters

spectively. Then, index $\{s, t\}$ holds for forces provided by suspensions and tires respectively. $\{x, y, z\}$ holds for forces and dynamics in the longitudinal, lateral and vertical axes respectively. Then let $v=\sqrt{v_{x}^{2}+v_{y}^{2}}$ denote the vehicle speed, $R_{i j}=R-\left(z_{u s_{i j}}-z_{r_{i j}}\right)$ the effective tire radius, $m=m_{s}+m_{u s_{f l}}+m_{u s_{f r}}+m_{u s_{r l}}+m_{u s_{r r}}$ the total vehicle mass, $\delta=\delta_{d}+\delta^{+}$is the steering angle $\left(\delta_{d}\right.$, the driver steering input and $\delta^{+}$, the additional steering angle provided by the steering actuator (see Section III) and $T_{b_{i j}}$ the braking torque provided by the braking actuator (see Section III).

The model parameters are those of a Renault Mégane Coupé (see TABLE. I; more parameters values can be found in [14]), obtained during a collaborative study with the MIPS laboratory in Mulhouse, through identification with real data.

\section{VEHICLE MODELING}

In this section, two models are introduced. A 3-DOF bicycle nonlinear vehicle model is used to design a coupled nonlinear flat vehicle control. The other one is an extended bicycle model used for the proposed LPV/H $\mathcal{H}_{\infty}$ control strategy. Some simplifying hypotheses are assumed for both of them:

- Longitudinal speed considered as different from zero $\left(V_{x}>\epsilon\right)$.

- Low steering angles: $\cos (\delta) \simeq 1$

Moreover, for the $\mathrm{LPV} / \mathcal{H}_{\infty}$ control, some additional assumptions are needed to linearize the model:

- Low sideslip angles: $|\beta|<7$ deg

- Low longitudinal slip ratios: $|\lambda|<0.1$

\section{A. 3DoF Nonlinear Two Wheels Vehicle Control Model}

The 3DoF-NLTWVM provides a sufficient approximation of the longitudinal and lateral dynamics of the vehicle. The 3DOF which compose this model are: longitudinal $V_{x}$, lateral $V_{y}$ and yaw $\dot{\psi}$ motions (see TABLE. I for notations). The coupled equations of this model are:

$$
\left\{\begin{array}{l}
m a_{x}=m\left(\dot{V}_{x}-\dot{\psi} V_{y}\right)=\left(F_{x 1}+F_{x 2}\right) \\
m a_{y}=m\left(\dot{V}_{y}+\dot{\psi} V_{x}\right)=\left(F_{y 1}+F_{y 2}\right) \\
I_{z} \ddot{\psi}=M_{z 1}+M_{z 2}
\end{array}\right.
$$

The forces and moments of equations (1) in the vehicle coordinates considering the kinetics coupling are:

$$
\left\{\begin{array}{l}
F_{x 1}=F_{x f} \cos (\delta)-F_{y f} \sin (\delta) \text { and } F_{x 2}=F_{x r} \\
F_{y 1}=F_{x f} \sin (\delta)+F_{y f} \cos (\delta) \text { and } F_{y 2}=F_{y r} \\
M_{z 1}=l_{f}\left(F_{y f} \cos (\delta)+F_{x f} \sin (\delta)\right) \text { and } M_{z 2}=-l_{r} F_{y r}
\end{array}\right.
$$

In Eq. (1) the longitudinal forces are computed using the dynamical model of the wheels. Considering the small angles assumption, and replacing the forces expressions in the model yield:

$$
\dot{x}=f(x, t)+g(x) u+g_{1} u_{1} u_{2}+g_{2} u_{2}^{2}
$$

where

$$
\begin{gathered}
f=\left[\begin{array}{c}
\dot{\psi} V_{y}-\frac{I_{r}}{m R}\left(\dot{\omega}_{r}+\dot{\omega}_{f}\right) \\
-\dot{\psi} V_{x}+\frac{1}{m}\left(-C_{f}\left(\frac{V_{y}+L_{f} \dot{\psi}}{V_{x}}\right)-C_{r}\left(\frac{V_{y}-L_{r} \dot{\psi}}{V_{x}}\right)\right) \\
\frac{1}{I_{z}}\left(-L_{f} C_{f}\left(\frac{V_{y}+L_{f} \dot{\psi}}{V_{x}}\right)+L_{r} C_{r}\left(\frac{V_{y}-L_{r} \dot{\psi}}{V_{x}}\right)\right)
\end{array}\right], \\
g=\left[\begin{array}{cc}
\frac{1}{m R} & \frac{C_{f}}{m}\left(\frac{V_{y}+L_{f} \dot{\psi}}{V_{x}}\right) \\
0 & \left(C_{f} R-I_{r} \dot{\omega}_{f}\right) / m R \\
0 & \left(L_{f} C_{f} R-L_{f} I_{r} \dot{\omega}_{f}\right) / I_{z} R
\end{array}\right], g_{1}=\left[\begin{array}{c}
0 \\
\frac{1}{m R} \\
\frac{L_{f}}{I_{z} R}
\end{array}\right], \\
g_{2}=\left[\begin{array}{c}
\frac{-C_{f}}{m} \\
0 \\
0
\end{array}\right]^{T}, x=\left[\begin{array}{c}
V_{x} \\
V_{y} \\
\dot{\psi}
\end{array}\right]^{T}, u=\left[\begin{array}{c}
u_{1} \\
u_{2}
\end{array}\right]
\end{gathered}
$$

where the longitudinal movement is controlled via the traction $T_{m}$ and braking $T_{b}$ wheel torque $u_{1}=T_{\omega}=T_{m}-T_{b}$ with $T_{b}=T_{b f}+T_{b r}$, and the lateral movement is controlled via the steering angle $u_{2}=\delta$ (see [18] for more details on this model).

\section{B. Extended bicycle model}

This model highlights the main non linear dynamics that influence vehicle safety and manoeuvrability, namely, the side-slip $(\beta)$ and yaw $(\psi)$ dynamics, given by:

$$
\left\{\begin{aligned}
m v \dot{\beta}= & F_{t y_{f}}+F_{t y_{r}}+m v \dot{\psi} \\
I_{z} \ddot{\psi}= & l_{f}\left(-F_{t x_{f}} \sin (\delta)+F_{t y_{f}} \cos (\delta)\right)-l_{r} F_{t y_{r}} \\
& -\Delta F_{t x_{r}} t_{r}+M_{d z}
\end{aligned}\right.
$$

where $F_{t y_{f}}=F_{t y_{f l}}+F_{t y_{f r}}, F_{t y_{r}}=F_{t y_{r l}}+F_{t y_{r r}}$ and $\Delta F_{t x_{r}}=F_{t x_{r l}}-F_{t x_{r r}}$ are the front, rear tire lateral forces and longitudinal rear differential forces, respectively. 
$\delta$ and $M_{d z}$ denote the steering angle and the yaw moment disturbance, respectively. $\Delta F_{t x_{r}}$ may be rewritten as,

$$
\Delta F_{t x_{r}}=F_{t x_{r l}}-F_{t x_{r r}}=\frac{\alpha}{2}\left(T_{b_{r l}}-T_{b_{r r}}\right)
$$

where, $\alpha=Q \mu R m_{r} g$ : is used o deduce the provided braking torque from the tire forces. The model used for the LPV/H $\mathcal{H}_{\infty}$ control design is given by (6):

Remark 1: The authors stress that the differences between the two model are due to the architecture of each control. Indeed, the flatness control is a non linear control strategy based on a non linear model while the LPV/H $\mathcal{H}_{\infty}$ one uses a linearized model. Also, to cope with each strategy's design, the authors have chosen different state space representations, but with the same control inputs $\left(\delta\right.$ and $T_{b}$ ).

\section{Design of The Vehicle dynamics Control STRATEGIES}

This section is devoted to the description of the main result of this paper, namely, the multivariable vehicle dynamics controller involving front active steering, rear braking with the two proposed strategies.

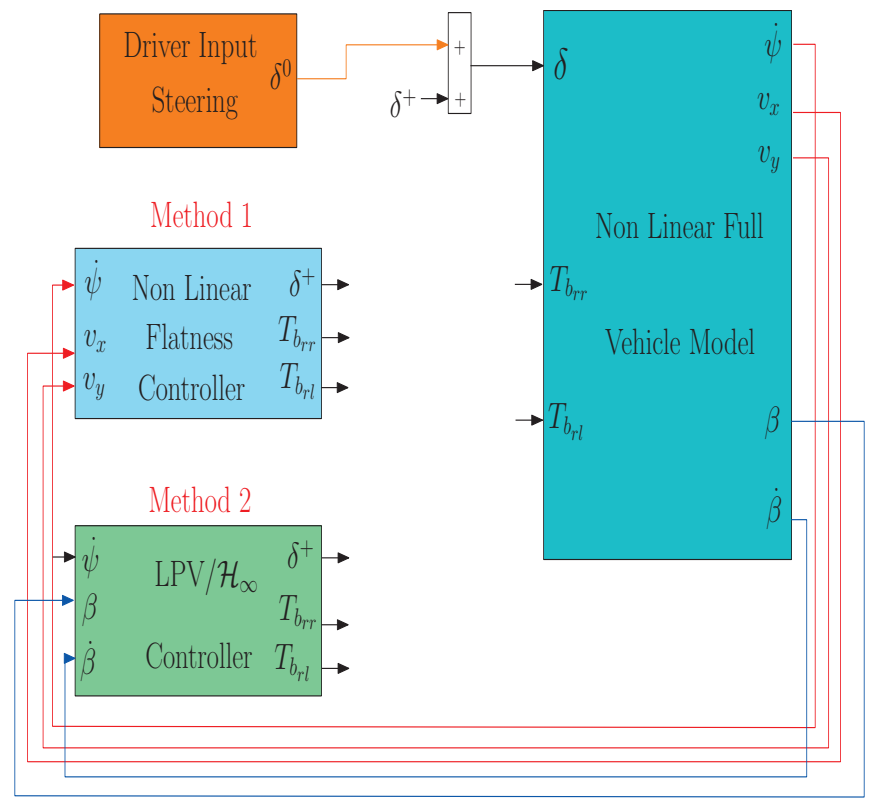

Fig. 1. Design of The Vehicle dynamics Control Strategies

\section{A. Coupled longitudinal/lateral vehicle non linear control based on flatness property}

The proposed non linear flatness control strategy, shown in fig.2, involves two main parts: the first one consists on the filtering and numerical differentiation of the flat outputs, while the second illustrates the different parts of the flat non linear vehicle control design.

1) Algebraic nonlinear estimation: In this work, the algebraic estimation techniques are used for their interesting properties in filtering and numerical differentiation of the noisy signals. This estimation is performed using the recent advances in [20], [21], which yield efficient real-time filters.

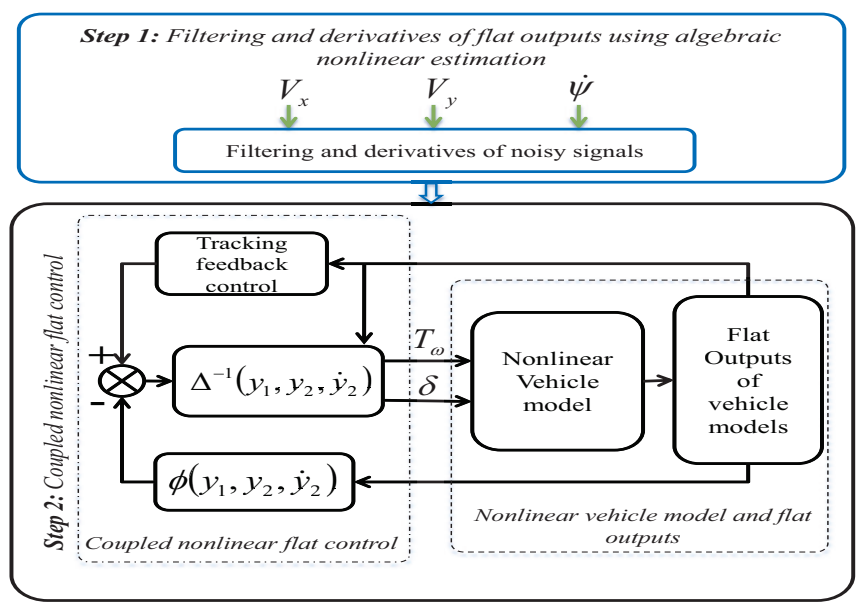

Fig. 2. Diagram block of coupled longitudinal and lateral vehicle control

Here, these estimators are used to design the flat control (11) and the feedback loop (12). The following formulae may be used to estimate the $1^{\text {st }}$ order derivative of $y$ :

$$
\hat{\dot{y}}(t)=-\frac{3 !}{n^{3}} \int_{t-n}^{t}(2 n(t-\tau)-n) y(\tau) d \tau
$$

the filtered version of $y$ is:

$$
\hat{y}(t)=\frac{2 !}{n^{2}} \int_{t-n}^{t}(3(t-\tau)-n) y(\tau) d \tau
$$

Note that the sliding time window $[t-n, t]$ may be quite short and $n$ is the sample period.

2) The non linear flatness control problem formulation: In order to design a coupled longitudinal and lateral flat vehicle control, consider the following flat outputs:

$$
\left\{\begin{array}{l}
y_{1}=V_{x} \\
y_{2}=L_{f} m V_{y}-I_{z} \dot{\psi}
\end{array}\right.
$$

The flatness property [17], [22]-[24] is used to show the flatness of model (3) with flat outputs (9). Then, after some algebraic manipulations the following flatness proofs are obtained:

$$
\left[\begin{array}{c}
x=\left[\begin{array}{ccc}
V_{x} & V_{y} & \dot{\psi}
\end{array}\right]_{y_{1}}^{T}=A\left(y_{1}, y_{2}, \dot{y}_{2}\right)= \\
\frac{1}{L_{f} m}\left(\begin{array}{c}
y_{2}-\frac{I_{z} L_{f} m y_{1} \dot{y}_{2}+I_{z} C_{r}\left(L_{f}+L_{r}\right) y_{2}}{C_{r}\left(L_{f}+L_{r}\right)\left(I_{z}-L_{r} L_{f} m\right)+\left(L_{f} m y_{1}\right)^{2}} \\
C_{r}
\end{array}\right) \\
-\left(\frac{L_{f} m y_{1} \dot{y}_{2}+C_{r}\left(L_{f}+L_{r}\right) y_{2}}{C_{r}\left(L_{f}+L_{r}\right)\left(I_{z}-L_{r} L_{f} m\right)+\left(L_{f} m y_{1}\right)^{2}}\right)
\end{array}\right]
$$

and

$$
\begin{gathered}
{\left[\begin{array}{l}
\dot{y}_{1} \\
\ddot{y}_{2}
\end{array}\right]=\Delta\left(y_{1}, y_{2}, \dot{y}_{2}\right)\left(\begin{array}{l}
u_{1} \\
u_{2}
\end{array}\right)+\Phi\left(y_{1}, y_{2}, \dot{y}_{2}\right)} \\
\Rightarrow\left[\begin{array}{l}
u_{1} \\
u_{2}
\end{array}\right]=\Delta^{-1}\left(y_{1}, y_{2}, \dot{y}_{2}\right)\left(\left[\begin{array}{c}
\dot{y}_{1} \\
\ddot{y}_{2}
\end{array}\right]-\Phi\left(y_{1}, y_{2}, \dot{y}_{2}\right)\right)
\end{gathered}
$$

The terms $\Delta_{11}, \Delta_{12}, \Delta_{21}, \Delta_{22}, \Phi_{1}$ and $\Phi_{2}$ of the matrices $\Delta$ and $\Phi$ are detailed in [18]. Finally, the system (3) is flat 


$$
\left[\begin{array}{l}
\dot{\beta} \\
\ddot{\psi}
\end{array}\right]=\left[\begin{array}{cc}
\mu \frac{-C_{f}-C_{r}}{m v} & 1+\mu \frac{l_{r} C_{r}-l_{f} C_{f}}{m v^{2}} \\
\mu \frac{l_{r} C_{r}-l_{f} C_{f}}{I_{z}} & \mu \frac{-l_{f}^{2} C_{f}-l_{r}^{2} C_{r}}{I_{z} v}
\end{array}\right]\left[\begin{array}{c}
\beta \\
\dot{\psi}
\end{array}\right]+\left[\begin{array}{cccc}
\frac{C_{f}}{m v} & 0 & 0 & 0 \\
\frac{l_{f} C_{f}}{I_{z}} & \frac{1}{I_{z}} & -\frac{\mu m_{r} g R t_{r}}{2 I_{z}} & \frac{\mu m_{r} g R t_{r}}{2 I_{z}}
\end{array}\right]\left[\begin{array}{c}
\delta \\
M_{d z} \\
T_{b_{r l}} \\
T_{b_{r r}}
\end{array}\right]
$$

with the flat outputs (9). Then, it is considered to control $y_{1}$ and $y_{2}$ via the control signals $u_{1}=T_{\omega}$ and $u_{2}=\delta$. Then, in order to track the desired output $y_{1}^{r e f}$ and $y_{2}^{r e f}$, set

$$
\left[\begin{array}{l}
\dot{y}_{1} \\
\ddot{y}_{2}
\end{array}\right]=\left[\begin{array}{c}
\dot{y}_{1}^{r e f}+K_{1}^{1} e_{y_{1}}+K_{1}^{2} \int e_{y_{1}} d t \\
\ddot{y}_{2}^{r e f}+K_{2}^{1} \dot{e}_{y_{2}}+K_{2}^{2} e_{y_{2}}+K_{2}^{3} \int e_{y_{2}} d t
\end{array}\right]
$$

where, $e_{y_{1}}=y_{1}^{r e f}-y_{1}$ and $e_{y_{2}}=y_{2}^{r e f}-y_{2}$. The choice of the gain parameters $K_{1}^{1}, K_{1}^{2}, K_{2}^{1}, K_{2}^{2}$ and $K_{2}^{3}$ is straightforward.

\section{B. $L P V / \mathcal{H}_{\infty}$ control design based on the braking/steering monitoring system}

In this part, the LPV/H $\mathcal{H}_{\infty}$ strategy proposed for vehicle stabilization and performance improvement is presented in Fig. 3, involving front active steering, rear braking, scheduled by a stability index parameter based on lateral side-slip dynamic monitoring.

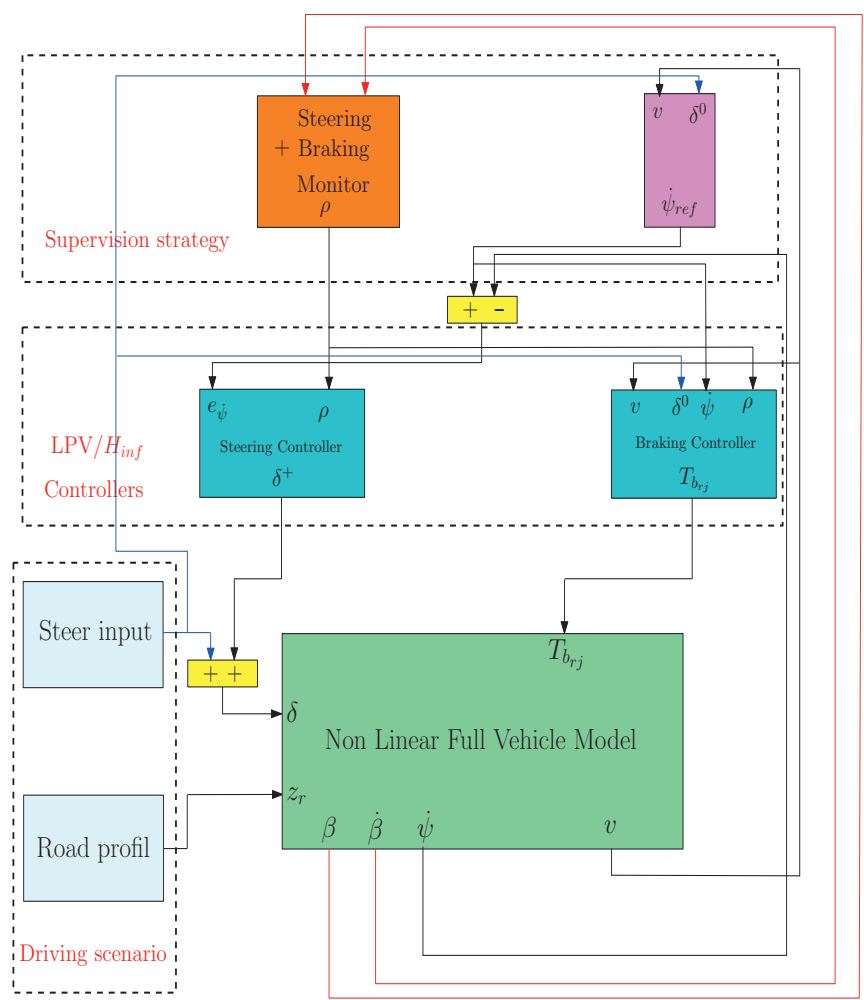

Fig. 3. Global chassis control Implementation scheme.

1) $L P V / \mathcal{H}_{\infty}$ control problem formulation: Many braking and steering controls have been already introduced by the authors as in [14]. The LPV/H $\mathcal{H}_{\infty}$ control synthesis follows the given $\mathcal{H}_{\infty}$ control problem in Fig. 4, where:

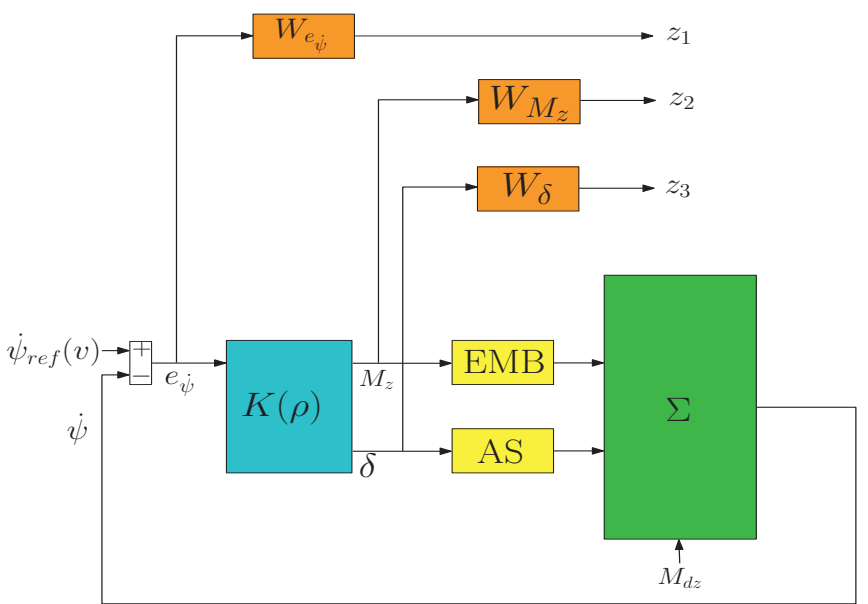

Fig. 4. Generalized plant model.

- $\Sigma$, EMB and AS stand for the extended bicycle, electromechanical braking and active steering actuators models, respectively.

- $z_{1}$, the yaw rate error output signal, is the output of the tracking error performance, weighted by:

$$
W_{e_{\dot{\psi}}}=\frac{1}{2 G_{e}} \frac{s G_{e} / 2 \pi f_{1}+1}{s / 2 \pi f_{1}+1}
$$

where $f_{1}=1 \mathrm{~Hz}$ is the cut-off frequency of the high pass filter. $G_{e}=0.1$ is the attenuation level for low frequencies $\left(f<f_{1}\right)$; in this case 0.1 means that the steady state tracking error should be less than $10 \%$.

- $z_{2}$, the yaw moment control signal attenuation, is the output of the braking control, weighted by:

$$
W_{M_{z}}(\rho)=\rho \frac{s /\left(2 \pi f_{2}\right)+1}{s /\left(\alpha 2 \pi f_{2}\right)+1}
$$

where $f_{2}=10 \mathrm{~Hz}$ and $\alpha=100$ are the braking actuator bandwidth and the roll-off parameters, respectively. These parameters are chosen to handle the dynamical braking actuator limitations. $W_{M_{z}}(\rho)$ is linearly parametrized by the considered varying parameter $\rho($.), where $\rho \in\{\rho \leq \rho \leq \bar{\rho}\}$ (with $\rho=0$ and $\bar{\rho}=1$ ). Then, when $\rho=\bar{\rho}$, the braking input is penalized, on the contrary, when $\rho=\rho$ the braking control signal is relaxed.

Remark 2: Notice that the braking torques $T_{b_{r l}}$ and $T_{b_{r r}}$ can be easily reconstructed through:

$$
\Delta T_{b_{r}}=T_{b_{r l}}-T_{b_{r r}}=\frac{2 M_{z}^{*} R_{w}}{t_{r}} .
$$

where $t_{r}$ is the vehicle's rear axle length, and $R_{w}$ is the effective tire radius. 
- $z_{3}$, the steering control signal attenuation, is the output of the steering control performance, weighted by:

$$
\begin{aligned}
W_{\delta} & =G_{\delta}^{0} \frac{\left(s / 2 \pi f_{3}+1\right)\left(s / 2 \pi f_{4}+1\right)}{\left(s / \alpha 2 \pi f_{4}+1\right)^{2}} \\
G_{\delta}^{0} & =G_{\delta} \frac{\left(\Delta_{f} / \alpha 2 \pi f_{4}+1\right)^{2}}{\left(\Delta_{f} / 2 \pi f_{3}+1\right)\left(\Delta_{f} / 2 \pi f_{4}+1\right)} \\
\Delta_{f} & =2 \pi\left(f_{4}+f_{3}\right) / 2
\end{aligned}
$$

where $G_{\delta}=5.10^{-3}, f_{4}=10 \mathrm{~Hz}$ is the steering actuator bandwidth and $f_{3}=1 \mathrm{~Hz}$ is lower limit of the actuator intervention.

The generalized plant is given by:

$$
\Sigma:\left\{\begin{array}{l}
\dot{\xi}(t)=A \xi(t)+B_{1} w(t)+B_{2}(\rho) u(t) \\
z(t)=C_{1}(\rho) \xi(t)+D_{11} w(t)+D_{12}(\rho) u(t) \\
y(t)=C_{2} \xi(t)+D_{21} w(t)
\end{array}\right.
$$

with :

$$
\begin{aligned}
w(t) & =\left[\dot{\psi}_{\text {ref }}(v)(t), M_{d z}(t)\right]^{T} & & \text { the exogenous inputs } \\
u(t) & =\left[\delta^{*}(t), M_{z}^{*}(t)\right]^{T} & & \text { the control inputs } \\
y(t) & =e_{\dot{\psi}}(t) & & \text { the measurements } \\
z(t) & =\left[z_{1}(t), z_{2}(t), z_{3}(t)\right]^{T} & & \text { the controlled outputs }
\end{aligned}
$$

$\xi(t)$ contains the state variables of the vehicle model, actuators and parameter dependent weighting functions.

The LPV controller is given by :

$$
K(\rho)\left\{\begin{array}{l}
\dot{x}_{c}(t)=A_{c}(\rho) x_{c}(t)+B_{c}(\rho) y(t) \\
\left(\begin{array}{c}
\delta^{*}(t) \\
M_{z}^{*}
\end{array}\right)=C_{c}(\rho) x_{c}(t)
\end{array}\right.
$$

where $x_{c}(t)$ is the controller state, $y(t)=e_{\dot{\psi}}, u(t)=$ $\left[\delta^{*}(t) M_{z}^{*}\right]^{T}$.

Remark 3: The design of the LPV/H $\mathcal{H}_{\infty}$ controller presented here, is achieved thanks to the LMI's resolution (for more detail see [25]).

2) Lateral braking/steering monitoring system for Scheduling parameter generation: This supervision strategy (as in [26]) is based on the supervision of the lateral stability of the vehicle. The stability bound defined in [27] and used here, is formulated as:

$$
\chi<1
$$

where $\chi=|2.49 \dot{\beta}+9.55 \beta|$ is the "Stability Index". Therefore, when the vehicle states move beyond the control boundaries and enter the unstable region, braking actuators will be involved to generate an additive corrective yaw moment, pulling the vehicle back into the stable region. According to [27], one of the significant benefits of this stability index is that the reference region defined in (20) is largely independent of the road surface conditions and hence, the accurate estimation of the road surface coefficient of friction is not required.

In this control strategy, the varying parameter is scheduled as a function of $\chi$ the activation of the actuators:

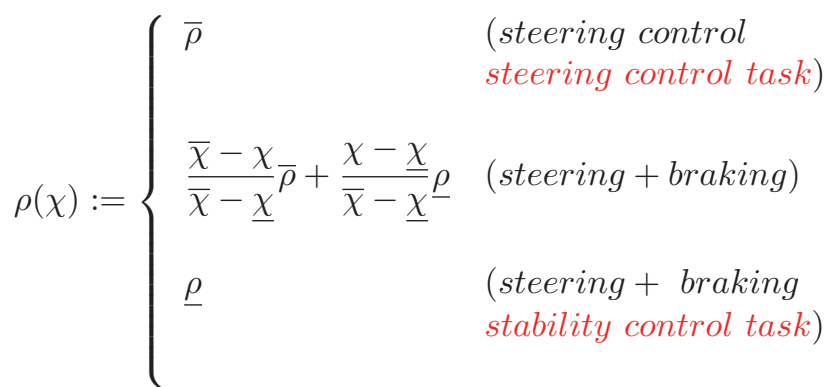

where $\underline{\chi}=0.8$ (user defined) and $\bar{\chi}=1$.

Remark 4: To generate the stability index $\chi$ used in this approach, a side-slip dynamics observer is used to evaluate $\dot{\beta}$ and $\beta$ (the sideslip) in real-time ( $\beta$ is not available using standard sensors, and thus, it must be estimated).

\section{Simulation Results}

Simulations are performed on the full vehicle non linear model of the Renalt Mégane coupé. The same simulation scenario is applied for the two proposed control strategies: The vehicle runs at $90 \mathrm{~km} / \mathrm{h}$ in straight line on wet $\operatorname{road}(\mu=$ 0.5 , where $\mu$ is a coefficient representing the road adhesion). During this scenario, a line change manoeuvre is performed by the driver.

In the following, a comparison between the different results obtained by the two proposed methods and the uncontrolled vehicle is shown.

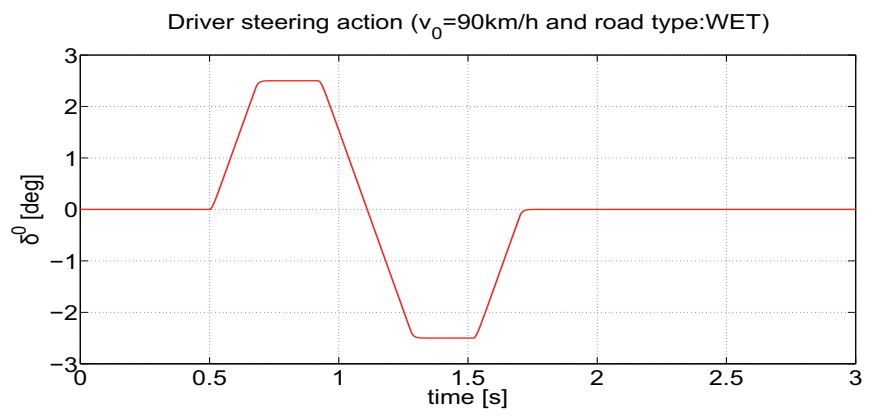

Fig. 5. Driver steering input signal.

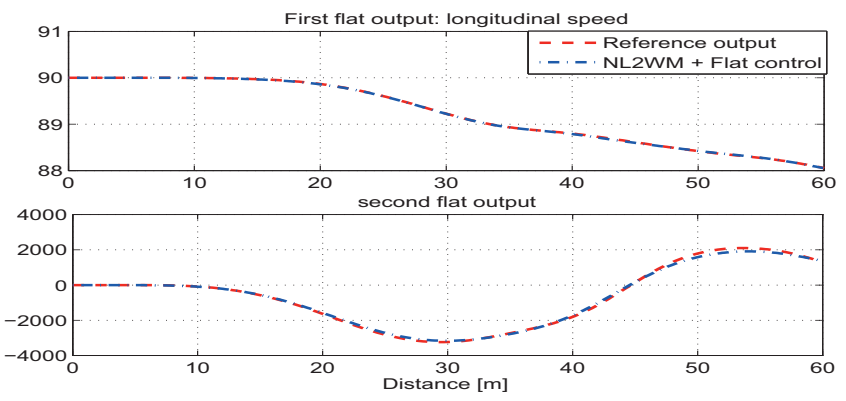

Fig. 6. Flat outputs: reference and controlled model

Fig. 6 shows the performance results of the flat controller to track the desired flat outputs $y_{1}$ and $y_{2}$. It is obvious that 
the proposed control approach ensures a perfect tracking of the desired outputs. Moreover, the abilities of this control strategy to provide coupled and realistic control maneuvers in terms of steering angle and braking torque are presented in Fig.9.

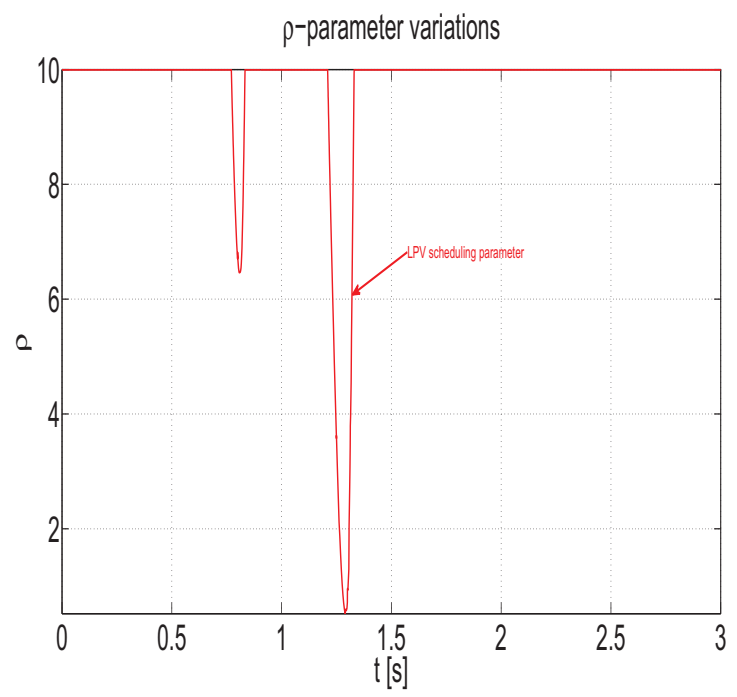

Fig. 7. the scheduling parameter : $\rho$

The Fig.7 shows the varying parameter that schedules the activation of the braking and steering actuators through the proposed LPV/H $\mathcal{H}_{\infty}$ conrol approach. The variation of this parameter allows to use the most appropriate actuator control to enhance optimally the stability of the vehicle.

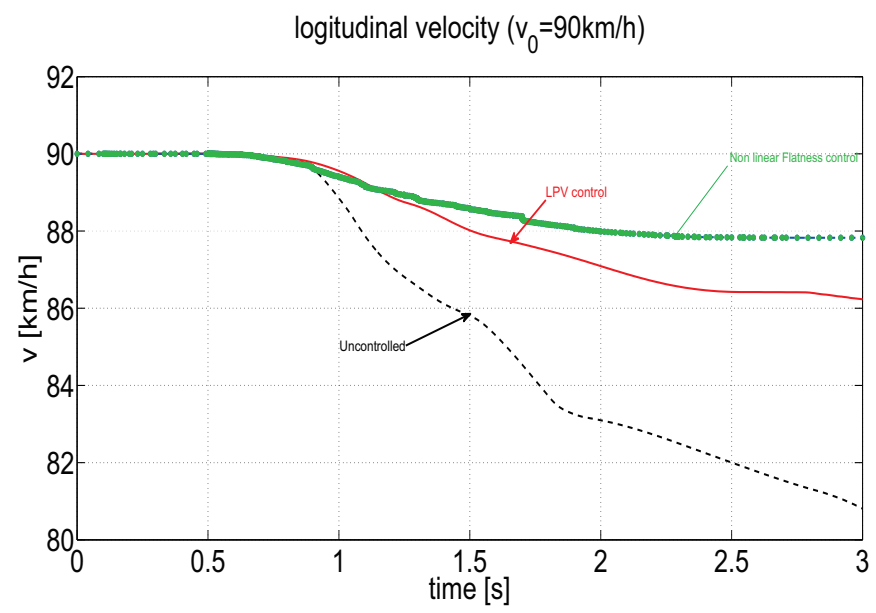

Fig. 8. Vehicle longitudinal speed: LPV/H $\mathcal{H}_{\infty}$ and Non linear Flatness control.

The Fig.8 shows a comparison between the longitudinal velocity tracking of the two methods. It can be noticed that the two control approaches improve well the tracking. The non linear flatness controller seems to be very efficient for the velocity tracking because of the design structure of strategy which focuses on this objective.

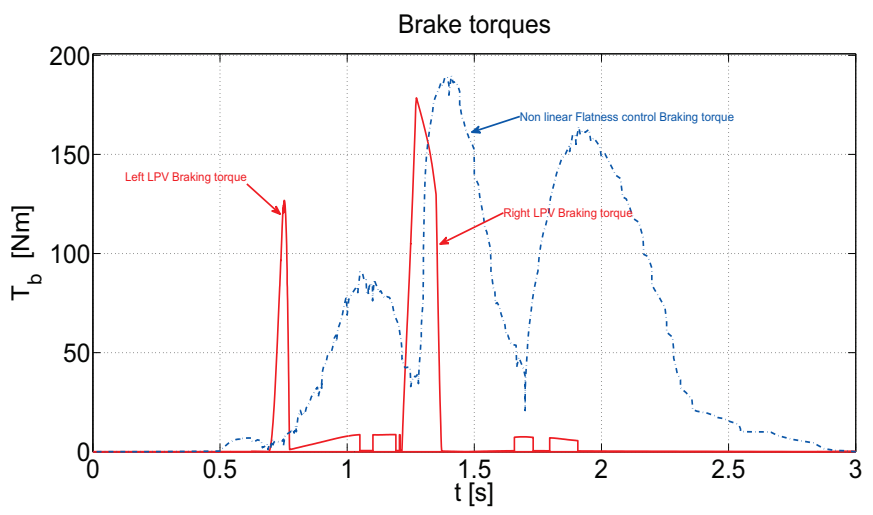

Fig. 9. Braking torques: LPV/H $\mathcal{H}_{\infty}$ and Non linear Flatness control.

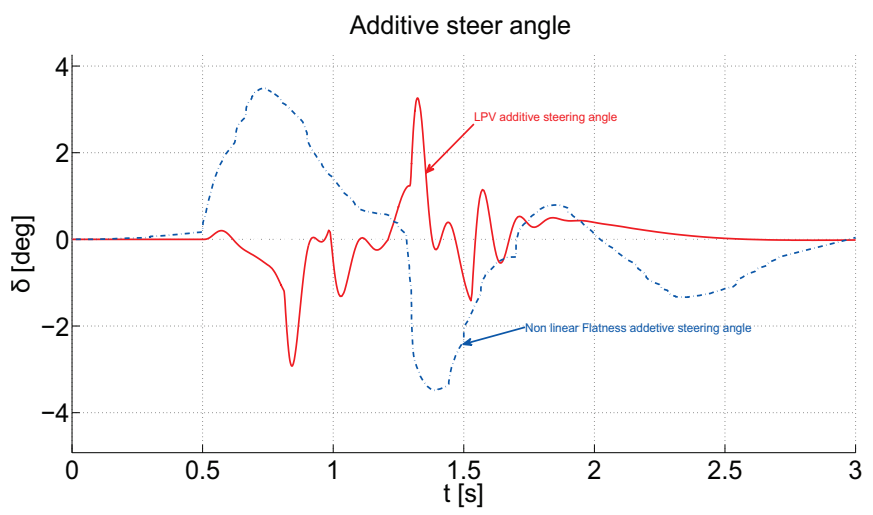

Fig. 10. Additive steering angle: $\mathrm{LPV} / \mathcal{H}_{\infty}$ and Non linear Flatness control.

Fig.9 presents the braking torques supplied by the considered Electro-Mechanical Braking actuators (no traction is considered here, $T_{\omega}=-T_{b}$ ). Also, Fig.10 represents the additive steering angles provided by the two perviously presented strategies. In the LPV/H $\mathcal{H}_{\infty}$ case, the braking and steering actuator's controllers outputs are scheduled by the previously presented varying parameter $\rho$ xhich leads to an effective and reduced use of the braking actions. The provided controllers actions help to enhance the vehicle safety in the dangerous driving situations.

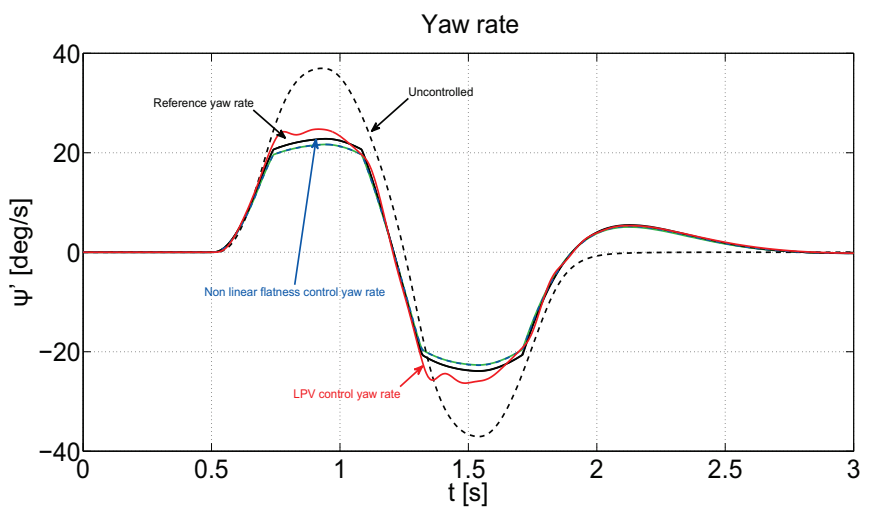

Fig. 11. Yaw rate: $\mathrm{LPV} / \mathcal{H}_{\infty}$ and Non linear Flatness control.

In Fig.11, it is clearly seen that either the LPV/H $\mathcal{H}_{\infty}$ strategy or the non linear Flatness control strategy enhances 
very well the lateral behaviours of the vehicle. Unlike the uncontrolled vehicle, simulations show that the yaw rate of he controlled vehicle, in both cases, is close to the reference car yaw rate. The reference car's yaw rate is plotted, here, to emphasize on the improvement brought by the proposed controllers.

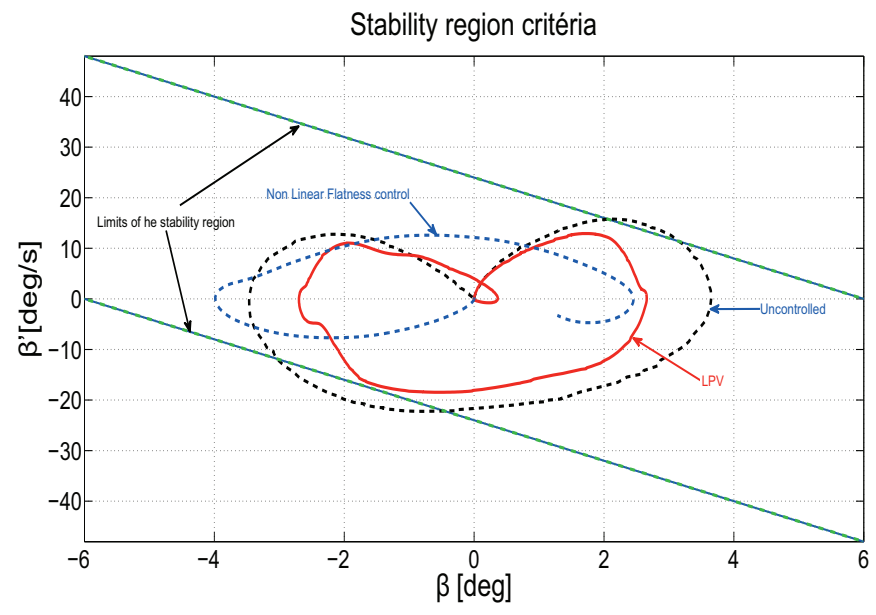

Fig. 12. Evolution of the vehicle in the $\beta-\dot{\beta}$ plane.

Fig.12 shows the main result of the paper in term of vehicle stability. The evolution of the vehicle into the stability region (bounded by the stability criteria, see [27]) is highlighted. It can be clearly noticed that the vehicle governed by the $\mathrm{LPV} / \mathcal{H}_{\infty}$ or the non linear Flatness controller stays within the limits of the stability region while the uncontrolled one, subject to the same conditions, goes beyond these bounds. Hence, the stability of the controlled car is completely ensured and the manoeuvrability of the vehicle is maintained in the critical driving situations.

In that simulation framework, the LPV controller seems to be more efficient than the non linear Flatness controller. Actually, it can be noticed that the yaw tracking performances in the LPV case are as good as in the flatness control case while using less steering and especially braking actuators and also with less complicated controller design synthesis. Indeed, part of the explanation may be also that the simulations are performed on a full Non Linear vehicle model under wet road conditions, while the design of the strategies has been done on bicycle models under dry road conditions. Also, the LPV strategy allows to activate the braking and steering actuators, through the scheduling by the varying parameter $\rho$, only when needed.

The LPV approach, which comes from the robust control theory, seems here more robust than the non linear one.

\section{CONCLUSiON}

This paper has presented two global chassis control strategies, involving braking and steering actuators. The first one is a non linear flatness control approach, the other one is an $\mathrm{LPV} / \mathcal{H}_{\infty}$ control approach. The non linear flatness control is based on an algebraic estimation while the LPV one is based on a lateral stability monitoring system. The results have proven the efficiency of the two strategies for the vehicle stability improvement even if one is linear and the other one is non linear. Indeed, the $\mathrm{LPV} / \mathcal{H}_{\infty}$ control strategy allows a smooth transition between performance objectives, and to treat non linearities in a simple way, while remaining robust through the $\mathcal{H}_{\infty}$ frame work.

Further works will try to combine the strength of the two methods through the LPV/H $\mathcal{H}_{\infty}$ control based on an algebraic estimation of some signals.

\section{REFERENCES}

[1] M. Denny, "The dynamics of antilock brake systems," European Journal of Physics, vol. 26, pp. 1007-1016, 2005.

[2] T. Johansen, I. Petersen, J. Kalkkuhl, and J. Ludemann, "Gainscheduled wheel slip control in automotive brake systems," IEEE Transaction on Control System Technology, vol. 11, no. 6, pp. 799811, 2003.

[3] S. Savaresi, M. Tanelli, and C. Cantoni, "Mixed slip-deceleration control in automotive braking systems," ASME Transactions: Journal of Dynamic Systems, Measurement and Control, vol. 129, no. 1, pp. 20-31, 2007.

[4] M. Tanelli, R. Sartori, and S. Savaresi, "Combining slip and deceleration control for brake-by-wire control systems: a sliding-mode approach," European Journal of Control, vol. 13, no. 6, pp. 593-611, december 2007.

[5] J. Ackermann and T. Bunte, "Yaw disturbance attenuation by robust decoupling of car steering," in Proceedings of the 13th IFAC World Congress (WC), San Francisco, California, june 1996, pp. 1-6.

[6] J. Villagra, B. d'Andréa Novel, H. Mounier, and M. Pengov, "Flatnessbased vehicle steering control strategy with SDRE feedback gains tuned via a sensitivity approach," IEEE Transaction on Control System Technology, vol. 15, no. 3, pp. 554-565, may 2007.

[7] S. Mammar and D. Koenig, "Vehicle handling improvement by active steering," Vehicle System Dynamics, vol. 38, no. 3, pp. 211-242, september 2002.

[8] E. Rossetter and J. Gerdes, "A study of lateral vehicle control under a virtual force framework," in Proceedings of the International Symposium on Advanced Vehicle Control, Hiroshima, Japan, 2002.

[9] M. Canale, L. Fagiano, M. Milanese, and P. Borodani, "Robust vehicle yaw control using an active differential and imc techniques," Control Engineering Practice, vol. 15, no. 8, pp. 923-941, january 2007.

[10] P. Gáspár, Z. Szabó, and J. Bokor, "Side force coefficient estimation for the design of an active brake," in Proceedings of the IEEE American Control Conference (ACC), Mineapolis, Minesota, june 2006, pp. 2927-2932.

[11] M. Doumiati, O. Sename, L. Dugard, J. Martinez-Molina, P. Gáspár, and Z. Szabó., "Integrated vehicle dynamics ccntrol via coordination of active front steering and rear braking," To appear in EJC.

[12] J. Tjønnås and T. Johansen, "Stabilization of automotive vehicles using active steering and adaptive brake control allocation," IEEE Transaction on Control System Technology, vol. 18, no. 3, pp. 545558, May 2010.

[13] B. Guvenç, T. Acarman, and L. Guvenç, "Coordination of steering and individual wheel braking actuated vehicle yaw stability control," in IEEE Intelligent Vehicle Symposium, Columbus, OH, USA, June 9-11 2003, pp. 288-293.

[14] C. Poussot-Vassal, O. Sename, L. Dugard, and S. M. Savaresi, "Vehicle dynamic stability improvements through gain-scheduled steering and braking control," Vehicle System Dynamics, vol. 49:10, pp. 1597-1621, March 2011.

[15] M. Doumiati, O. Sename, J. Martinez, L. Dugard, and C. PoussotVassal, "Gain-scheduled lpv/H $\mathcal{H}_{\infty}$ controller based on direct yaw moment and active steering for vehicle handling improvements," in Decision and Control (CDC), 2010 49th IEEE Conference on, dec. 2010, pp. $6427-6432$.

[16] C. Poussot, O. Sename, S. Fergani, M. Doumiati, and L. Dugard, "Global Chassis Control Using Coordinated Control of Braking/Steering Actuators", Robsut Control And Linear Parameter Approaches: Application to Vehicle Dynamics, O.Sename, P. Gáspár, and J. Bokor, Eds. Springer, 2013. 
[17] M. Fliess, J. Lévine, P. Martin, and P. Rouchon, "A lie-bäcklund approach to equivalence and flatness of nonlinear systems," IEEE Trans. Automat. Control, vol. 44, pp. 922-937, 1999.

[18] L. Menhour, B. d'Andréa Novel, C. Boussard, M. Fliess, and H. Mounier, "Algebraic nonlinear estimation and flatness-based lateral/longitudinal control for automotive vehicles," in Proceedings of the 14th Int. IEEE Conf. ITS, Washington, usa, 2011.

[19] S. Fuchshumer, K. Schlacher, and T. Rittenschober, "Nonlinear vehicle dynamics control - a flatness based approach," in Proceedings of the $44^{\text {th }}$ IEEE CDC \& ECC, Sevilla, 2005.

[20] M. Fliess, C. Join, and H. Sira-Ramírez, "Non-linear estimation is easy," Int. J. Model. Identif. Control, vol. 4, pp. 12-27, 2008.

[21] M. Mboup, C. Join, and M. Fliess, "Numerical differentiation with annihilators in noisy environment," Numer. Algor., vol. 50, pp. 439467, 2009.

[22] M. Fliess, J. Lévine, P. Martin, and P. Rouchon, "Flatness and defect of nonlinear systems: introductory theory and examples," International Journal of Control, vol. 61, pp. 1327-1361, 1995.

[23] J. Lévine, Analysis and Control of Nonlinear Systems - A Flatnessbased Approach. Springer, 2009.

[24] H. Sira-Ramírez and S. Agrawal, Differentially Flat Systems. Marcel Dekker, 2004

[25] M. Doumiati, O. Sename, J. Martinez, L. Dugard, and C. PoussotVassal, "Lpv/hinf controller for vehicle handling and stability enhancement," in Proceedings of the 12th mini-conference on Vehicle System Dynamics, Identification and Anomalies (VSDIA'10), Budapest,HU, november 2010.

[26] M. Moustapha, O. Sename, L. Dugard, J. Martinez-Molina, P. Gàspàr, and Z. Szabo, "Nonlinear optimal integrated vehicle control using individual braking torque and steering angle with on-line control allocation by using state-dependent riccati equation technique," to in EJC.

[27] J. He, D. Crolla, M. Levesley, and W. Manning, "Coordination of active steering, driveline, and braking for integrated vehicle dynamics control." Proc. Inst. Mech Engineers, vol. PartD: Automobile Engineering, 2006. 